Голубева Татьяна Михайловна, Поскребышева Татьяна Александровна РИТОРИЧЕСКИЕ СРЕДСТВА КОНСТРУИРОВАНИЯ ОБРАЗА ИГИЛ В АМЕРИКАНСКОМ

\title{
ПОЛИТИЧЕСКОМ ДИСКУРСЕ
}

В статье проводится анализ риторических средств, участвующих в создании образа ИГИЛ в американском политическом дискурсе. Материалом для данного исследования послужили официальные выступления представителей американского правительства, в которых затрагивается тема военной кампании США 2017-2018 гг., направленной на борьбу с запрещенной в России террористической организацией "ИГИЛ" - "Исламское государство Ирака и Леванта". Подробно описано, какие риторические приемы обусловливают воспроизводство и поддержание у целевой аудитории представлений о преступности, антигуманности и враждебности этой организации.

Адрес статьи: www.gramota.net/materials/2/2018/5-1/14.html

\section{Источник}

Филологические науки. Вопросы теории и практики

Тамбов: Грамота, 2018. № 5(83). Ч. 1. С. 71-75. ISSN 1997-2911.

Адрес журнала: www.gramota.net/editions/2.html

Содержание данного номера журнала: www.gramota.net/materials/2/2018/5-1/

\section{() Издательство "Грамота"}

Информация о возможности публикации статей в журнале размещена на Интернет сайте издательства: www.gramota.net Вопросы, связанные с публикациями научных материалов, редакция просит направлять на адрес: phil@gramota.net 
8. Конъуратлы К. Чал атымнынъ тырнагъы (Копыто моей чалой лошади) // Крым: литературно-художественный журнал. 2013. № 4 (35). С. 286-292.

9. Короглу Л. А. Идеографический словарь языка И. Гаспринского. Симферополь: ИП Хотеева Л. В., 2017.104 с.

10. Крымскотатарско-русско-украинский словарь: в 3-Х т. / сост. С. М. Усеинов. Симферополь: СОНАТ, 2002 . Т. І. 473 с.

11. Мазинов А. С. Греческие и итальянские заимствования в крымскотатарском языке: дисс. ... к. филол. н. Киев, 2004.221 с.

12. Меметов А. М. Лексикология крымскотатарского языка. Симферополь: Крымучпедгиз, 2000.288 с.

13. Садыкова 3. Р. Зоонимическая лексика татарского языка: монография. Казань: Татарское кн. изд-во, 1994.130 с.

14. Севортян Э. В. Этимологический словарь тюркских языков. Общетюркские и межтюркские лексические основы на букву «Къ». М.: Индрик, 2000. 261 с.

15. Севортян Э. В. Этимологический словарь тюркских языков. Общетюркские и межтюркские основы на букву «Б». М.: Наука, 1978. 349 с.

16. Сеферова Ф. А. Место животных в древних воззрениях крымских татар (на материале крымскотатарских сказок) // Вопросы крымскотатарской филологии, истории и культуры. Симферополь, 2017. Вып. 1 (4). С. $74-77$.

17. Хатипова Э. А. Къырымтатар халкъ йырларында ат-алаша тимсали (Символ лошади в крымскотатарских народных песнях) // Труды НИЦ крымскотатарского языка, литературы, истории и художественной культуры. Симферополь, 2011. T. 1. C. 311-315.

18. Щербак А. М. Названия домашних и диких животных в тюркских языках // Историческое развитие лексики тюркских языков. М.: Наука, 1961. С. 82-172.

19. Эбзеева Ф. П. Карачаево-балкарская зоонимия: автореф. дисс. ... д. филол. н. Нальчик, 2013.59 с.

\section{SEMANTIC FIELD OF THE ZOONYM “HORSE” IN THE CRIMEAN TATAR LANGUAGE}

Ganieva Emine Suleimanovna, Ph. D. in Philology, Associate Professor Crimean Engineering and Pedagogical University, Simferopol

emineg59@mail.ru

The article is devoted to a relevant problem of the Crimean Tatar sectoral vocabulary - horse breeding terms. The paper analyzes lexico-semantic groups, which include the words expressing the age and gender peculiarities of a horse, terms characterizing its nature and physical condition, coat colour names. The author examines the lexemes transferring the animal's functional characteristics, gaits. The study is based on the comparative analysis of all-Turkic vocabulary, vocabulary of certain Turkic languages and Crimean Tatar vocabulary proper.

Key words and phrases: Crimean Tatar language; lexical system; semantic field; lexico-semantic group; zoo-lexeme.

УДК 81 '42:811.111

https://doi.org/10.30853/filnauki.2018-5-1.14

Дата поступления рукописи: 14.02.2018

В статье проводится анализ риторических средств, участвующих в создании образа ИГИЛ в американском политическом дискурсе. Материалом для данного исследования послужили официальные выступления представителей американского правительства, в которых затрагивается тема военной кампании США 2017-2018 г2., направленной на борьбу с запрещенной в России террористической организачией «ИГИЛ»«Исламское государство Ирака и Леванта». Подробно описано, какие риторические приемы обусловливают воспроизводство и поддержание у целевой аудитории представлений о преступности, антигуманности и враждебности этой организации.

Ключевые слова и фразы: метафоры; деперсонификация; неодушевленные существительные; метонимия; имя собственное «ИГИЛ».

Голубева Татьяна Михайловна, к. филол. н.

Поскребышева Татьяна Александровна, к. пед. н., доцент

Нижегородский государственный технический университет имени Р. Е. Алексеева

gtm212@mail.ru; sentireo@mail.ru

\section{РИТОРИЧЕСКИЕ СРЕДСТВА КОНСТРУИРОВАНИЯ ОБРАЗА ИГИЛ В АМЕРИКАНСКОМ ПОЛИТИЧЕСКОМ ДИСКУРСЕ}

Взаимодействие языка и общества является предметом многочисленных социолингвистических исследований, проводимых с опорой на концептуально-методологическую базу критического дискурс-анализа. Представители данного научного направления анализируют как завуалированные, так и прозрачные случаи проявления доминирования, дискриминации, власти и контроля в языке. Наиболее эксплицитно отношения между языком и властью проявляются в политическом дискурсе. Изучением особенностей использования языковых и риторических средств в данном виде дискурса занимаются такие зарубежные и отечественные ученые, как П. Чилтон [3], Т. А. ван Дейк [5], Р. Водак, Г. Вайс [4], А. П. Чудинов [1]. Данное исследование выполнено 
в обозначенном теоретическом формате и имеет целью охарактеризовать риторические средства, участвующие в конструировании образа ИГИЛ в американском политическом дискурсе. Материалом для дискурс-анализа послужили выступления представителей американского правительства, в которых затрагивается тема военной кампании США на Ближнем Востоке 2017-2018 гг., направленной на борьбу с запрещенной в России международной террористической организацией «ИГИЛ». Актуальность работы обусловлена ростом интереса к комплексному исследованию политического дискурса, а также необходимостью изучения и описания роли риторических средств и приемов в формировании у реципиента определенного отношения к предмету высказывания.

Дискурсивный анализ показывает, что в своих выступлениях для характеристики «ИГИЛ» американские политики применяют различные метафорические номинации. Так, например, госсекретарь США Рекс Тиллерсон в своем докладе на вашингтонской конференции глав стран-участников коалиции по борьбе с «ИГИЛ» от 22 марта 2017 года использует экспрессивные метафоры, концептуализирующие ИГИЛ как источник смертельной угрозы для всего мирового сообщества. В частности, он называет эту террористическую организацию «глобальной силой зла», призывая всех собравшихся приложить максимальные усилия для ее поражения: The great commonality among we who have gathered today is a commitment to bringing down a global force of evil [10]. / Всех нас, кто собрался сегодня здесь, объединяет намерение покончить с этой глобальной силой зла (здесь и далее перевод авторов статьи. - T. Г., Т. П.). Американский госсекретарь также уподобляет экстремистскую деятельность ИГИЛ «глобальной вспышке», подобной вспышке опасной эпидемии, грозящей унести жизни тысяч людей: We know military strength will stop ISIS on a battlefield, but it is the combined strength of our coalition that will be the final blow to ISIS. In order to stay ahead of a global outbreak, we must all adopt the following countermeasures [Ibidem]. / Мы знаем, что наша военная мощь остановит ИГИЛ на поле боя, но только единая мощь нашей коаличии окончательно сокрушит ИГИЛ. Для того чтобы предупредить глобальную вспышку, мы должны принять следующие контрмеры. Кроме того, Р. Тиллерсон сравнивает ИГИЛ с ядовитым растением, разбрасывающим свои семена ненависти по всему миру: As we stabilize areas encompassing ISIS's physical caliphates in Iraq and Syria, we also must prevent their seeds of hatred from taking root elsewhere [Ibidem]. / Сейчас, когда мы занимаемся стабилизацией обстановки на территориях, охватьвающих халифаты ИГИЛ в Ираке и Сирии, мы должны предотвратить распространение их семян ненависти по всему миру. В докладе перед студентами и сотрудниками Стэндфордского университета от 17 января 2018 года американский госсекретарь использует эмоционально выразительное метафорическое выражение have оne foot in the grave («быть одной ногой в могиле»), обусловливающее представление ИГИЛ как больного и/или старого человека, находящегося на пороге смерти: ISIS presently has one foot in the grave, and by maintaining an American military presence in Syria until the full and complete defeat of ISIS is achieved, it will soon have two [11]. I В настоящее время ИГИЛ одной ногой находится в могиле, и, если мы сохраним американское военное присутствие в Сирии вплоть до окончательного и полного разгрома ИГИЛ, он будет двумя ногами в могиле. Данная метафора позволяет актуализировать уязвимость, непрочность и недолговечность этой террористической организации и тем самым разрушить представления о ее военной мощи и непобедимости. В другом высказывании, обращаясь с призывом к аудитории «сломать каждое звено в цепочке ИГИЛ», Р. Тиллерсон, наоборот, метафорически концептуализирует ИГИЛ как предмет неживой природы - некий сложный и бездушный механизм: ISIS is connected across every continent and we must work to break every link in its chain [10]. / ИГИЛ имеет связи на всех континентах, и мы должны сломать каждое звено в его цепочке. В свою очередь, министр обороны США Джеймс Мэттис во время пресс-конференции в Тель-Авиве 20 апреля 2017 года также употребляет глагол break, но уже для описания действий вооруженных сил США по отношению к ИГИЛ: The battle was going on, and we were going to use what was necessary to break ISIS [7]. / Во время сражения мыл были готовы применить любое оружие, чтобы сломить ИГИЛ. Использование этих метафор позволяет говорящим актуализировать чуждость объекта номинации, в данном случае - ИГИЛ, миру людей и тем самым обосновать правомерность и целесообразность применения любых средств для его устранения.

Представление ИГИЛ как механического объекта при помощи специальных метафор сопровождается концептуализацией самих членов террористической организации как неживых предметов. В своих высказываниях для наименования боевиков ИГИЛ американские политики вместо таких общепринятых обозначений, как fighters («бойцы»), terrorists («террористы») и militants («боевики»), используют неодушевленное существительное elements («элементы»). Так, например, Дж. Мэттис заявляет, что «войска коалиции ведут борьбу с элементами ИГИЛ в Афганистане»: In this case, in Afghanistan, they have been engaged in that fight up in that corner against ISIS elements up there for some time [Ibidem]. / В течение некоторого времени они воевали против элементов ИГИЛ в Афганистане. На пресс-конференции от 19 января 2018 года старший сотрудник государственного департамента США говорит о том, что «элементы» ИГИЛ покинули зону боевых действий: But beyond the Euphrates, ISIS elements in northern Syria, also in northern Iraq, have chosen not to fight and die but have moved out of the combat area, regrouping [2]. / Однако за Евфратом элементы ИГИЛ, находящиеся на севере Сирии и на севере Ирака, предпочли не воевать и погибнуть, а выйти из зоны военных действий. В рассмотренных примерах используется риторический прием деперсонификации или овеществления: естественнонаучный термин, обозначающий предметы неживой природы, служит для наименования людей. Подобные обезличивающие наименования, как правило, носят уничижительный характер, обусловливая снижение статуса объекта номинации. Ранее было отмечено, что позиционирование террористов как обезличенных предметов актуализирует их чуждость миру людей. Усиление эффекта чуждости в речи американских политиков 
достигается благодаря контекстуальному противопоставлению этих опасных «элементов» мирным гражданам США. Так, например, на пресс-конференции во Флориде 6 апреля 2017 года Р. Тиллерсон заявляет о том, что «элементы на территории Сирии, завладевшие химическим оружием, представляют прямую угрозу для американского народа»: There are elements on the ground in Syria, elements that are plotting to reach our shore, and these types of weapons falling into their hands and being brought to our shore is a direct threat to the American реорle [10]. / В Сирии есть элементы, замышляюшие добраться до наших берегов, и если они завладеют химическим оружием, то будут представлять прямую угрозу американскому народу. Помимо существительного elements («элементы») для обозначения боевиков ИГИЛ американские политики используют неодушевленное существительное remnants («остатки»). Так, например, генерал Джеймс Глинн, заместитель командующего войсками США в Ираке и Сирии, на пресс-конференции в Багдаде 16 января 2018 года говорит о том, что «остатки ИГИЛ все еще существуют в виде отдельных ячеек»: There are still remnants of ISIS who reside in a cellular structure who seek to bring instability to local areas, in particular population centres [6]. / Ocmamки ИГИЛ все еще существуют в виде отдельных ячеек. Они стремятся создать нестабильность на территории своего проживания, особенно в густонаселенных иентрах. На пресс-конференции для журналистов от 19 января 2018 года представитель государственного департамента США заявляет о том, что действия американских военных направлены на борьбу с последними остатками ИГИЛ в долине реки Евфрат: What we're after now is the enduring remnants of ISIS as well as the bits and pieces of that territorial entity still present in the Euphrates Valley [2]. / Наша цеель-последне остатки ИГИЛ, а также части этого территориального образования, все еще существующие в долине реки Евфрат.

В конструировании образа ИГИЛ принимает участие и другой риторический прием - метонимия. Метонимический перенос основан на связи между словами по смежности. Так, в речи американских политиков имя собственное “ISIS" («ИГИЛ») часто употребляется в качестве субститута словосочетания ISIS fighters/terrorists («боевики/террористы ИГИЛ»). Госсекретарь Р. Тиллерсон в своем докладе использует словосочетания ISIS's carnage («резня ИГИЛ») и ISIS's hatred («ненависть ИГИЛ») вместо более точных по смыслу выражений carnage of ISIS fighters и hatred of ISIS terrorists: Many of us here today represent countries who know ISIS's carnage firsthand. <..> As we commemorate and mourn for the victims of ISIS's hatred, let us also honor them with unwavering dedication to victory [10]. / Многие из тех, кто собрался сегодня здесь, представляют страны, которые непосредственно испытали на себе резню ИГИЛ. <...> Сейчас, когда мыл скорбим по жертвам ненависти ИГИЛ, давайте почтим их память непоколебимой верой в победу. Генерал Дж. Глинн в своей речи употребляет обобщенное выражение the evil of ISIS («зло ИГИЛ») вместо более конкретного the evil of ISIS terrorists: The campaign against ISIS has resulted in over 4.5 million people liberated from the evil of ISIS [6]. / Военная кампания по борьбе с ИГИЛ привела к освобождению более четырех с половиной миллионов людей от зла ИГИЛ. В данных высказываниях метонимический перенос обусловливает не только создание эмоционально выразительного образа. Использование метонимии позволяет сфокусировать внимание реципиента на антигуманной природе этой экстремистской организации, преступном характере ее идеологии, подчеркнуть масштабность ее угрозы для человечества, а также усилить обличительный тон высказывания. В таких словосочетаниях, как ISIS's capabilities [Ibidem] («возможности ИГИЛ»), ISIS's defeat [11] («поражение ИГИЛ»), ISIS's propaganda («пропаганда ИГИЛ»), ISIS's best weapon («лучшее оружие ИГИЛ»), ISIS's new call [10] («новый призыв ИГИЛ»), метонимический перенос способствует не только компрессии информации. Благодаря частому употреблению акронима “ISIS”" вместо одушевленного существительного “fighters” или “terrorists” ИГИЛ воспринимается не как конкретная организация, конкретное сообщество вооруженных людей, занимающихся террористической деятельностью, а как некое обезличенное абстрактное образование - вездесущая «глобальная сила зла», порождающая ненависть и жестокость, несущая с собой разрушение и смерть, угрожающая жизни и благополучию людей.

В ходе анализа были выявлены и другие случаи метонимического употребления имени собственного «ИГИЛ». Так, например, в докладе эмиссара президента США по делам международной антитеррористической коалиции Бретта МакГерка присутствует словосочетание live under ISIS («жить при ИГИЛ»). Появление в языке такого выражения обусловлено социальными факторами. По сведениям СМИ, действия боевиков ИГИЛ по отношению к мирным жителям, как правило, отличались варварством и жестокостью: на захваченных территориях они нередко устраивали массовые расправы с представителями религиозных и этнических меньшинств с целью устрашения гражданского населения. Выражение live under ISIS («жить при ИГИЛ»), которое использует в своей речи Б. МакГерк, по-видимому, означает жить при «террористическом режиме ИГИЛ». В данном случае имя собственное “ISIS" выступает в роли метонима словосочетания the ISIS terrorist regime: Four million people who were living under ISIS just a couple years ago are no longer living under ISIS [8]. / Четыре миллиона человек, которые жили при террористическом режиме ИГИЛ пару лет назад, уже больше не живут при режиме ИГИЛ. В этом же выступлении Б. МакГерк использует словосочетание аfter ISIS («после ИГИЛ»), выполняющее в предложении синтаксическую функцию обстоятельства времени. В речи госсекретаря Р. Тиллерсона присутствует аналогичное выражение in the wake of ISIS («после ИГИЛ»), только в данном случае вместо временного предлога употребляется устойчивое номинативное словосочетание. Благодаря использованию временных указателей after, in the wake of ИГИЛ концептуализируется как некое значительное событие, произошедшее в ближневосточном регионе. Очевидно, в данном случае речь идет о длительной оккупации боевиками ИГИЛ населенных пунктов Ирака и Сирии. Таким образом, в данном контексте акроним “ISIS” является метонимом выражения the ISIS occupation: This campaign is not just 
about defeating ISIS. It's about defeating the ideology that ISIS represents, it's about liberating the population, and it's about working with local actors to return people to their homes after ISIS [Ibidem]. / Цель нашей кампании не только сокрушить ИГИЛ, но и сокрушить идеологию, которую представляет ИГИЛ, освободить население и наладить работу с местной администрацией, чтобы обеспечить возвращение людей домой после оккупации боевиками ИГИЛ. In the normalization phase, local leaders and local governments will take on the process of restoring their communities in the wake of ISIS with our support [Ibidem]. / В стадии нормализации обстановки местные руководители и администраџия с нашей помощью займутся восстановлением общественной жизни после оккупации боевиками ИГИЛ.

Интересными с лингвистической точки зрения представляются случаи употребления имени собственного «ИГИЛ» в функции описательного определения в двухкомпонентных номинативных словосочетаниях. Так, например, Р. Тиллерсон в своей речи использует выражения ISIS content и ISIS material, в которых смысловое содержание акронима “ISIS" является идентичным значению слов “extremist”, “terrorist”. Как известно, члены организации «ИГИЛ» вели активную деятельность в социальных сетях, создавая там собственные аккаунты с целью размещения в них материалов экстремистского и террористического характера и вербовки будущих террористов. В результате ИГИЛ стал прочно ассоциироваться с пропагандой экстремизма и терроризма в Интернете. Данный социальный феномен способствовал появлению в английском языке таких выражений, как ISIS content [Ibidem], ISIS material [Ibidem], ISIS propaganda [6], в которых имя собственное «ИГИЛ» означает «экстремистские/террористические идеи ИГИЛ»: These efforts have yielded a 75 percent reduction of ISIS content on the internet in one year, and the takedown of 475,000 ISIS-linked Twitter accounts... Researchers in the United States are already developing tools for sweeping the dark corners of the internet for ISIS material [10]. / Благодаря этим усилиям произошло снижение объема интернетконтента, содержацего экстремистские идеи ИГИЛ, на 75 прочентов и удаление 475 тысяч аккаунтов, связанных с ИГИЛ, в социальной сети «Твиттер»... Американские специалисты уже разрабатывают способы очистки темных углов Интернета от материалов, содержащии экстремистские идеи ИГИЛ.

Проведенный анализ установил, что в конструировании образа ИГИЛ участвуют такие средства риторики, как метафора, деперсонификация и метонимия. Американские политики используют в своих выступлениях метафоры, обусловливающие представление террористической организации «ИГИЛ» как источника смертельной угрозы для мирового сообщества. Кроме того, при помощи метафор ИГИЛ концептуализируется как некий механизм, предмет неживой природы. Использование неодушевленных существительных «элементы», «остатки» для обозначения боевиков ИГИЛ (деперсонификация) позволяет говорящим актуализировать их чуждость миру людей. В речи американских политиков метонимия служит не только средством компрессии информации и придания речи дополнительной образности. Благодаря употреблению акронима «ИГИЛ» вместо выражения «боевики ИГИЛ» в словосочетаниях типа ISIS's carnage, ISIS's hatred, ISIS's best weapon, ISIS 's propaganda ИГИЛ воспринимается не как сообщество отдельных террористов, а как некое обезличенное абстрактное образование, «глобальная сила зла», несущая с собой разрушение и смерть. Таким образом, метонимия позволяет подчеркнуть серьезность и масштабность угрозы, которую представляет ИГИЛ для жизни людей. Использование имени собственного «ИГИЛ» в качестве субститута выражений «террористический режим ИГИЛ» и «оккупация боевиками ИГИЛ» обусловливает воспроизводство и поддержание представлений о преступности, антигуманности и враждебности этой организации. Благодаря четко выраженным отрицательно-оценочным коннотациям имя собственное «ИГИЛ» в некоторых случаях функционирует как синоним слов «экстремистский», «террористический».

Список источников

1. Чудинов А. П. Политическая лингвистика. М.: Флинта, 2006. 254 с.

2. Briefing on Syria by Senior State Department Official [Электронный pecypc]. URL: https://www.state.gov/r/pa/prs/ps/ 2018/01/277545.htm (дата обращения: 25.01.2018).

3. Chilton P. Analysing political discourse: theory and practice. L. - N. Y.: Roultledge, 2004. 226 p.

4. Critical discourse analysis: theory and interdisciplinarity / ed. by G. Weiss, R. Wodak. N. Y.: Palgrave MacMillan, 2002. 312 p.

5. Dijk T. A. van. Discourse and power. N. Y.: Palgrave MacMillan, 2008. 320 p.

6. Glynn J. Department of Defense Press Briefing by Brig. Gen. Glynn via Teleconference from Baghdad, Iraq [Электронный pecypc]. URL: https://www.defense.gov/News/Transcripts/Transcript-View/Article/1416545/ department-of-defense-pressbriefing-by-brig-gen-glynn-via-teleconference-from/ (дата обращения: 25.01.2018).

7. Mattis J. Media Availability with Secretary Mattis in Tel Aviv [Электронный pecypc]. URL: https://www.defense. gov/News/Transcripts/Transcript-View/Article/1158209/media-availability-with-secretary-mattis-in-tel-aviv/ (дата обращения: 12.11.2017).

8. McGurk B. Press Conference by Special Presidential Envoy McGurk in Baghdad, Iraq [Электронный ресурс]. URL: https://www.state.gov/s/seci/2017remarks/272547.htm (дата обращения: 25.01.2018).

9. McMaster H. Remarks with National Security Advisor H. R. McMaster [Электронный pecypc]. URL: https://www.state.gov/ secretary/20172018tillerson/remarks/2017/04/269543.htm (дата обращения: 12.11.2017).

10. Tillerson R. Remarks at the Ministerial Plenary for the Global Coalition Working to Defeat ISIS [Электронный ресурс]. URL: https:/www.state.gov/secretary/20172018tillerson/remarks/2017/03/269039.htm (дата обращения: 12.11.2017).

11. Tillerson R. Remarks on the Way Forward for the United States Regarding Syria [Электронный pecypc]. URL: https://www.state. gov/secretary/20172018tillerson/remarks/2018/01/277493.htm (дата обращения: 25.01.2018). 


\title{
RHETORICAL MEANS TO CONSTRUCT THE ISIL IMAGE IN THE AMERICAN POLITICAL DISCOURSE
}

\author{
Golubeva Tat'yana Mikhailovna, Ph. D. in Philology \\ Poskrebysheva Tat'yana Aleksandrovna, Ph. D. in Pedagogy, Associate Professor \\ Nizhny Novgorod State Technical University named after R. E. Alekseev \\ gtm212@mail.ru; sentireo@mail.ru
}

\begin{abstract}
The article provides an analysis of rhetorical means contributing to the creation of the ISIL (Islamic State of Iraq and the Levant) image in the American political discourse. The research is based on the official speeches of the representatives of the American government, who tackle the issue of the USA military campaign of 2017-2018 against the prohibited in Russia terroristic organization ISIL. The authors describe in detail what rhetorical devices influence target audience to form and maintain the conceptions of criminality, anti-humanism and enmity of this organization.
\end{abstract}

Key words and phrases: metaphors; depersonification; inanimate nouns; metonymy; proper name ISIL.

УДК 81.371

https://doi.org/10.30853/filnauki.2018-5-1.15

Дата поступления рукописи: 15.02.2018

В статье рассматриваются этимологические основы синонимических рядов (СР) прилагательных со значением «малая величина». Изучены дифференциальные признаки синонимов. Показано наличие среди прилагательных этимологически окрашенной лексики. Исследуются пути пополнения данного пласта английской лексики. Определено, что подавляюшее большинство исконных прилагательных данной лексико-семантической группь (ЛСГ) пополнялось в результате аффиксального словообразования. Доказано, что заимствования являются одним из наиболее продуктивных методов номинаиии в английском языке.

Ключевые слова и фразы: этимология; синонимический ряд; пространственные прилагательные размера; экспрессивность; заимствование.

Гринцова Ольга Васильевна, к. филол. н., доцент

Солманидина Наталья Викторовна, к. филос. н., доцент

Пензенский государственный университет архитектуры и строительства

english@pguas.ru; solomona@mail.ru

\section{ЭТИМОЛОГИЧЕСКИЕ ОСНОВЫ СИНОНИМИЧЕСКИХ РЯДОВ ПРИЛАГАТЕЛЬНЫХ СО ЗНАЧЕНИЕМ «МАЛАЯ ВЕЛИЧИНА» И ПУТИ ИХ ПОПОЛНЕНИЯ}

Пространство и время - это фундаментальные понятия языка и мышления, формы существования материи. Предметом исследования в данной статье являются пространственные прилагательные размера со значением «малая величина».

Основой для исследования послужили работы российских лингвистов И. В. Арнольд [1], В. М. Лейчика [2], А. Н. Лавровой [7], В. М. Солнцева [5].

При исследовании пространственных прилагательных авторы исходят из того, что язык как важнейшее средство человеческого общения относится к системным образованиям, обладающим своей собственной структурой, которая, в свою очередь, представляет собой определенное устройство, организацию, упорядоченность [Там же].

Актуальность исследования продиктована необходимостью более детального анализа системных связей и системной организации в пределах синонимических рядов как важных групп в лексическом составе английского языка и, соответственно, прилагательных со значением размера. Важным представляется комплексное изучение лексики, семитических особенностей и системных отношений с учетом того, что семантика языковых единиц есть форма выражения внеязыкового содержания.

Новизна исследования заключается в том, что, хотя отдельные прилагательные размера являлись предметом исследований, но общая картина функционально-семантических характеристик этого пласта лексики и его участия в построении системы семантических групп прилагательных английского языка не была детально разработана.

Цель работы: доказать, что синонимические ряды прилагательных со значением размера представляют собой закономерное явление в английской лексической системе. Цель исследования обусловила постановку следующих конкретных задач:

1) объединение лексических единиц в тематические группы;

2) установление количественных характеристик синонимических рядов;

3) классификация синонимов по происхождению;

4) сравнение членов синонимических рядов по источнику заимствования.

Теоретическая значимость исследования заключается в том, что оно вносит вклад в дальнейшее изучение прилагательных, в частности - в разработку проблем как образования прилагательных, так и выделения наиболее продуктивных способов их образования. 